\title{
Genetic distance of Malaysian Mousedeer based on mitochondrial DNA cytochrome oxidase I (COI) and D-loop region sequences
}

\author{
Mohamad-Azam Akmal Abu Bakar, a, Jeffrine Japning Rovie-Ryan², Ahmad \\ Ampeng ${ }^{3}$, Salmah Yaakop ${ }^{1}$, Shukor Md Nor ${ }^{1}$, Badrul Munir Md-Zain ${ }^{1, b}$ \\ 1 School of Environmental and Natural Resource Sciences, Faculty of Science and Technology, \\ Universiti Kebangsaan Malaysia, 43600, Selangor, Malaysia \\ 2Department of Wildlife and National Parks (PERHILITAN), Peninsular Malaysia, Kuala Lumpur, Malaysia \\ 3 Sarawak Forest Department, Petra Jaya, Kuching Sarawak
}

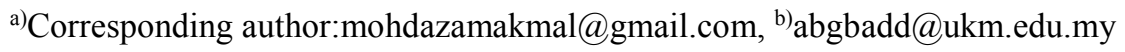

\begin{abstract}
Mousedeer is one of the primitive mammals that can be found mainly in Southeast-Asia region. There are two species of mousedeer in Malaysia which are Tragulus kanchil and Tragulus napu. Both species can be distinguish by size, coat coloration, and throat pattern but clear diagnosis still cannot be found. The objective of the study is to show the genetic distance relationship between $T$. kanchil and T. napu and their population based on mitochondrial DNA (mtDNA) cytochrome oxidase I (COI) and D-loop region. There are 42 sample of mousedeer were used in this study collected by PERHILITAN from different locality. Another 29 D-loop sequence were retrieved from Genbank for comparative analysis. All sample were amplified using universal primer and species-specific primer for COI and D-loop genes via PCR process. The amplified sequences were analyzed to determine genetic distance of $T$. kanchil and T. napu. From the analysis, the average genetic distance between T. kanchil and T. napu based on locus COI and D-loop were 0.145 and 0.128 respectively. The genetic distance between populations of $T$. kanchil based on locus COI was between 0.003-0.013. For locus D-loop, genetic distance analysis showed distance in relationship between west-coast populations to east-coast population of $T$. kanchil. COI and D-loop mtDNA region provided a clear picture on the relationship within the mousedeer species. Last but not least, conservation effort toward protecting this species can be done by study the molecular genetics and prevent the extinction of this species.
\end{abstract}

\section{INTRODUCTION}

Mousedeer are family of small ruminant that can be found widely in Mainland Asia: Myanmar, Thailand, Cambodia, Laos, Vietnam, Sumatra, Java and Malaysia [1]. There are two species of mousedeer which are Tragulus kanchil and Tragulus napu [1] [2]. T. kanchil is the smallest species of mousedeer with a body weight between 0.7 to $2.6 \mathrm{~kg}$ [1] [3] [4]. While T. napu is a larger mousedeer with body weight ranging from 3.5 to $6.0 \mathrm{~kg}$ [1] [4]. This sympatric species were diagnosed traditionally based on morphological characteristic including coat color, body size and throat pattern [2] [5]. Although it has been studied that these two species of mousedeer differ in term of size and coat color, but clear diagnostic still remains undiscovered.

Both species inhabit lowland primary forest and secondary forests [3]. T. kanchil is usually found below $100 \mathrm{~m}$, while T. napu was found to be at higher habitat. They feed on food mainly of young leaves, leaf shoots and fallen fruits [3] [4]. Mousedeer are mostly active foraging, dawn and dusk [6] [7]. They mostly move from shelter to shelter during the day and resting at night [7].

Although the Malaysian mousedeer are not considered endangered, the current decline in status have signaled serious concerns regarding the extinction possibilities. These animals start to be increasingly declining. Furthermore, these mousedeer species are one of source of food hunted by local people. The decline of mousedeer population will cause us to lose valuable genetic resources of this species. Globally, mousedeer is currently classified as vulnerable

The 2017 UKM FST Postgraduate Colloquium

AIP Conf. Proc. 1940, 020035-1-020035-6; https://doi.org/10.1063/1.5027950

Published by AIP Publishing. 978-0-7354-1632-1/\$30.00 